\title{
ETNOGRAFÍA DE LA TELEAUDIENCIA DE MEDELLÍN. Hábitos, uso y contextos de consumo
}

Mónica María Valle Flórez*, Elvia Lucía Ruíz Marín ${ }^{* *}$, Liliana Velásquez ${ }^{* * *}$,

Natalia Jaramillo Hernández ${ }^{* \star * *}$, Andrea Tobón Marín ${ }^{* * * *}$, Gloria Moreno Vélez******

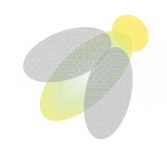

\section{Resumen}

En el artículo se presentan los hábitos, usos y contextos del consumo televisivo de la teleaudiencia de Medellín, uno de los objetivos planteados en el Estudio Etnográfico de la Teleaudiencia de Medellín, en Perspectiva de la TV Digital, adelantado por el Grupo de Investigación en Comunicación de la Facultad de Comunicación Audiovisual del Politécnico Jaime Isaza Cadavid. Proyecto en el que se explora además, el campo de sentido de "ver televisión" y la percepción que tienen los medellinenses acerca de la televisión pública y privada, en perspectiva de la televisión digital; resultados que se presentarán en posteriores artículos.

En esta etnografía, se abordaron familias de cada uno de los estratos representativos de las 16 comunas de la ciudad. Se observó, que las familias de Medellín siguen con frecuencia programas como: fútbol, reality shows, series (telenovelas), películas, noticias y programas de humor. Más que ver la "pantalla chica", se escucha. Entre zapping y zapping, el spoiler se posiciona como uno de los relatos televisivos más visualizados. El ritual de "ver TV" implica además, la conversación y la compañía, y es que la teleaudiencia de Medellín prefiere ver la TV en familia y con amigos. No faltan los comentarios y opiniones de programas, noticias, actores, etc. En semana, la tarde - noche es el horario habitual para "ver" la TV. Esta teleaudiencia, señala que la televisión no los tiene "amarrados", no les marca su rutina diaria, y que no esperan, ni siguen programas. Para los más jóvenes la TV es para "desparchados".

Palabras clave: Etnografía de audiencias, teleaudiencias de Medellín, televisión, usos de la TV, hábitos de consumo, familias y TV.

Recibido: 28 de mayo de 2014 - Aceptado: 28 de agosto de 2014

\begin{abstract}
*Mónica María Valle F. Doctora en Estudios Científico Sociales, Instituto Tecnológico de Occidente -ITESO (México). Magister en Comunicación de la Universidad Iberoamericana-UIA (México), Especialista en Gerencia de la Comunicación de la Universidad Pontifica Bolivariana (Colombia) y Comunicadora Social - Periodista de la Universidad de Antioquia (Colombia). Directora del Grupo de Investigación en Comunicación -GIC, Editora de la Revista Luciérnaga-Comunicación, http://www.politecnicojic.edu.co/luciernaga-10/ y de la Revista Intersección: Eventos, turismo, gastronomía y moda. http://www.politecnicojic.edu.co/revistas/interseccion/interseccion-1/ Docente e investigadora - Politécnico Colombiano Jaime Isaza Cadavid. Email: mmvalle@elpoli.edu.co
\end{abstract}

**Elvia Lucía Ruíz Marín. Especialista en Televisión de la Universidad Pontificia Bolivariana. Comunicadora Social de la Universidad de Antioquia. Docente e investigadora de la Facultad de Comunicación Audiovisual del Politécnico Colombiano Jaime Isaza Cadavid. Email: elruiz@elpoli.edu.co

*** Liliana Velásquez. Comunicadora Audiovisual del Politécnico Colombiano Jaime Isaza Cadavid, auxiliar en la investigación Etnografía de la Teleaudiencia de Medellín, en Perspectiva de la TV Digital. Email: lilola_7@hotmail.com

${ }^{* * * *}$ Natalia Jaramillo Hernández $\&{ }^{* * * * *}$ Andrea Tobón Marín. Comunicadoras Audiovisuales del Politécnico Colombiano Jaime Isaza Cadavid desarrollaron como trabajo de grado, prueba piloto de la investigación Etnografía de la Teleaudiencia de Medellín, en Perspectiva de la TV Digital, en la comuna 16 de Medellín. Email: naty.jara87@gmail.com

******Gloria Moreno Vélez. Comunicadora Social - Periodista, de la Universidad de Antioquia, Especialista en Mercadeo. Ha sido docente de Comunicación y Periodismo, Coordinadora Académica de la Facultad de Comunicación Audiovisual del Politécnico Colombiano Jaime Isaza Cadavid. Actualmente se desempeña en la dependencia de Regionalización de la misma institución. Email: gemoreno@elpoli.edu.co 


\section{INTRODUCCIÓN}

Los estudios de recepción se desarrollan a partir de los años 80, y se les consideran como una nueva corriente de investigación en relación con la audiencia. Corriente en la que se analiza los procesos a través de los cuales, éstas construyen significados a partir de su exposición a los medios. Desde esta perspectiva se considera a las audiencias agentes dinámicos. Para Klaus Bruhn Jesen (1992):

\begin{abstract}
“...Las audiencias tienen la capacidad de asignar su propio sentido a los medios de comunicación y en este proceso de recepción los medios satisfacen una gama de intereses y placeres legítimos de la audiencia".
\end{abstract}

Los estudios de audiencias, si bien tienen en cuenta a los perceptores y los contenidos mediáticos, enfatizan, también, en los contextos donde viven los receptores, ya que éstos crean los marcos idóneos dentro de los cuales los mensajes adquieren sentido. Es claro que la cotidianidad familiar se puede definir como contexto de recepción.

\begin{abstract}
“...La observación etnográfica del consumo televisivo por un televidente al interior de hogar aparece una situación de recepción que integra la recepción televisiva con el espaciotiempo propio de la cotidianidad de la vida familiar (Fuenzalida, 2006, especialmente cap 2); situación diversa de la recepción de otros consumos culturales en donde se abandona la cotidianidad del hogar para ingresar en otra situación de recepción, esto es, tiempoespacios especialmente acondicionados y con reglas propias como la sala de cine, de teatro, de espectáculos y conciertos, campos deportivos, aula de clases, biblioteca, lugar de trabajo, etc. (Fuenzalida, 2012).
\end{abstract}

La vida familiar cotidiana es el contexto en el que se mira la televisión y en el que se experimentan procesos de interacción y disfrute con el medio; es en el hogar donde la gente (a través de sus capacidades interpretativas y creativas), tiene sus propias ocupaciones y en la que dentro de él, experimenta relaciones con los medios de comunicación y otras formas simbólicas de comunicación (Lull, 1987, p320). En el estudio Televisión y Familia. Una experiencia etnográfica en la vida de tres hogares colimenses, se argumenta que:

"Lo cotidiano es un devenir, una presencia en la que el flujo de la televisión fluye también como una presencia diaria dentro de las familias" (Bautista, Covarrubia y Uribe en Lameiras \& Galindo, 1994, p.107).

La familia es un espacio social (Bourdieu, 1983), en el que se imponen normas y reglas que deben cumplirse para mantener relaciones de convivencia permanente. En ella se aprende a sentir, se adquieren las primeras relaciones de socialización, prácticas, acciones, valoraciones; es donde se incorporan los habitus de clase. La familia es un sistema complejo de relaciones sociales, de mediaciones (González, 1989).

Los estudios de recepción se interesan igualmente por los usos que se hace de los medios. Jesús Martín Barbero, con base en un estudio con escolares, plantea algunas tipologías en torno a los usos de la TV: uso "apasionado", uso "peor es nada" y uso "ambiental" de la TV [1]. Argumenta, que los estudios de recepción de televisión, son una corriente crítica que se aboca al análisis del uso social de los medios, como por ejemplo, el de adquirir un cierto poder y prestigio social para interactuar con "el otro". Bautista, Covarrubia y Uribe en el estudio Televisión y Familia. Una experiencia etnográfica en la vida de tres hogares colimenses (Lameiras \& Galindo, 1994 , p.111), encuentran "usos conscientes" y "usos inconscientes" de la televisión. Entre los conscientes: regulación del tiempo, agente de compañía, agente consejero, medio que da motivo de conversación, medio de entretenimiento y distracción, medio que permite tomar decisiones. Entre los "usos inconscientes" encuentran que la televisión en ciertas situaciones de la vida familiar es instrumento de poder: quien ve o no la Tv. También se tiene un "uso del medio como catarsis", este se presenta cuando la televisión proporciona estímulos dentro de sus contenidos que tocan las sensibilidades de los sujetos. La relación con el medio se vuelve vicaria, proporcionando al sujeto una especie de relax.

Para Neil Postman, los medios, en tanto crean el contenido de la cultura, son metáforas, de allí que los estudios de recepción deban enfocarse al análisis de los medios como lenguajes. Indica que la televisión es uno de los lenguajes con los que se percibe la realidad, en tal sentido ésta sería como sus lenguajes [2]. De acuerdo con esta perspectiva, Fiske (1987) resalta la importancia de estudiar los procesos de significación a partir de la articulación entre los textos y las audiencias. Guillermo Orozco, aporta a esta perspectiva dando cuenta del proceso en que los miembros de las audiencias apropian y producen sentido, proceso que es fundamentalmente sociocultural. Dice Orozco:

"[Las audiencias] entran en una "secuencia interactiva" que implica varios grados de involucramiento y procesamiento de contenido televisivo, dicha secuencia es "atención", "comprensión", "selección", "valoración de lo percibido", "almacenamiento" e "integración de informaciones anteriores".

Fiske, con la intención de reconocer que entre los espectadores de un programa hay diferencias que deben ser tomadas en cuenta, sugiere utilizar el término audiencias en plural, para desdibujar las implicaciones homogeneizadoras del término "audiencia" en singular. Dice Fiske, no hay una sociedad homogénea, sino que el sistema social está surcado por ejes de clase, género, raza, edad, nacionalidad, religión, política, etc., todos los cuales producen con mayor o menor fuerza marcadas diferencias, que implican, siempre, la dimensión de poder.

En el contexto de la oferta televisiva son varios los retos para los estudios de recepción. Para el mexicano Guillermo Orozco (1996), uno de ellos es la difícil tarea de observar las audiencias fragmentadas, efímeras, dispersas. Audiencias, que al parecer no hacen distinción entre el entretenimiento y las noticias, entre la política y el placer, etc. Para Orozco, se hace necesario entonces, entender a las audiencias como agentes, esto es:

"Como sujetos que se van constituyendo como tal de muchas maneras y diferenciando como resultado de su interacción particular con la televisión y, sobre todo, como consecuencia de las distintas mediaciones que entran en juego en su proceso de recepción".

Para el británico Morley (1996), el reto está en la capacidad de construir la audiencia como fenómeno social y cultural, y en la capacidad de reconocer la 
relación entre los televidentes y el aparato televisivo, en tanto en dichas relaciones están mediadas por determinaciones de la vida cotidiana y la vinculación de las audiencias con otras tecnologías mediáticas. Otros de los retos de los estudios de audiencias es aproximarse a lo que está haciendo la gente con, en y alrededor de los medios de comunicación (Gouldry, 2011), así como estudiar los efectos de la ira, el miedo, y el disfrute, mediados por los medios de comunicación. Emociones que pueden "infectar" rápidamente a comunidades enteras, naciones, e incluso a poblaciones, algunas veces con efectos catastróficos (Gibbs, 2011). El compromiso de la investigación de audiencias, debe pasar por el análisis de los contenidos de los medios, así como de sus "efectos culturales" de la visualización de contenido violento (Ruddock, 2011), también el estudio sobre los fans y los fandoms (Busse \& Gray, 2011) y de audiencias étnicamente diferenciadas (Madianou; 2011).

Para Fuenzalida (2012), con los receptores multimediales se abre un importante campo de investigación. Al respecto sugiere las siguientes preguntas: ¿Cómo es la recepción televisiva en el actual ambiente multimedia? ¿Qué construcciones intertextuales se realizan por parte de los usuarios multitasking? ¿Cuál interactividad ocurre frente a los programas televisivos? ¿Cuáles géneros de programas permanecerán como más atractivos? ¿Cuál será la relación de estos usuarios con los géneros informativos de la TV abierta y con la información intercambiada a través de redes sociales? ¿Persistirán algunas ficciones masivamente convocantes en salas de cine y en los canales de TV?

En cuanto a los métodos, David Deacon y Emily Keightley (2011) abogan por la utilización de métodos cuantitativos y cualitativos en el análisis de audiencias. Murphy (2011), señala que la etnografía de medios, en línea o virtual es clave, especialmente por la "desterritorialización de la cultura", para Murphy la etnografía de medios se expande para ocupar nuevos territorios como el de los personajes del mundo del video juego o el de las audiencias geográficamente dispersas. Por el contrario, Deger (2011) resalta la importancia de la investigación in situ, con fundamento en la intimidad y la inmediatez de la etnografía práctica que alcanzó al documentar sus experiencias de ver películas en DVD con su familia por adopción Yolngu, comunidad indígena australiana.

En el estudio que se presenta en este artículo se utilizó la Etnografía clásica para la observación del grupo familiar, por tratarse de audiencias situadas.

\section{METODOLOGÍA}

El estudio adelantado fue de carácter cualitativo y de magnitud descriptiva. Las familias seleccionadas para el estudio, fueron las de tipo tradicional, padre, madre e hijos; se prefirieron aquellas familias en las que había representación de hijos de ambos sexos, masculino y femenino. A cada familia se le otorgó un código, al igual que a cada miembro de la familia. Siendo la familia 1, la de estrato uno, la familia 2, la de estrato dos y así sucesivamente. A cada miembro de la familia se le otorgó un código, así: padre de estrato uno (P1), madre de este estrato (M1), hijo de estrato uno $(\mathrm{H} 1)$, hija de estrato uno (HA1), de igual manera se utilizó el código para los integrantes de las familiar de estratos $2,3,4,5$ y 6 .

Las familias se seleccionaron a conveniencia, teniendo en cuenta que fueran representativas de cada uno de los estratos socioeconómicos. Para lograr el acercamiento con las familias y la efectiva inmersión del investigador con los sujetos objeto de estudio, se realizaron 2 visitas de ambientación y sensibilización. En la primera, se les comentó acerca de la dimensión del estudio; investigadoras y familia compartieron un refrigerio. En la segunda visita, se firmó el consentimiento informado.

El proceso de observación se llevó a cabo de manera presencial por parte del investigador, durante 3 días a la semana y los demás días de la semana se contó con registro de video, el cual era activado por algún miembro de familia del estudio. También se utilizaron fichas de observación y registro, en las cuales se consignaron los "observables" de la cotidianidad de las familias: caracterización, rutinas, escenarios, mediaciones, consumo, usos, entre otros. El registro de la observación se realizó desde el 15 de noviembre hasta el 15 de diciembre de 2012.

\section{HALLAZGOS}

\subsection{Hábitos de consumo}

En la Etnografía de la Teleaudiencia de Medellín en Perspectiva de la TV Digital, se encontró como puntos comunes que los integrantes de las familias observadas [4]: padres, madres, hijos e hijas ven especialmente fútbol, reality shows, series (telenovelas), películas, noticias y programas de humor.

Para los padres observados no hay como ver la TV en la comodidad de la cama. "Ya va a empezar el partido" dice Padre 5, acomoda la almohada, agarra el control con una mano y con la otra el celular.

[Uno de los padres de estrato 3, está viendo el programa Gol Caracol, esperando a que empiece el partido Colombia - Brasil. Está muy concentrado viendo el partido y a veces se sienta en la cama porque piensa que van a hacer gol, en otras oportunidades habla solo de lo que ve y dice cosas como: "!Ay! así, así corre, corre ahhhh", [grita] "penalti” o "ahhhhhhhh juemadre"].

Los hijos (hombres) ven, especialmente el canal FOX Sports, y las hijas ocasionalmente fútbol.

Las madres observadas hacen comentarios sobre fútbol. Opinan constantemente sobre los jugadores, las jugadas que realizan y la emoción que les produce cada triunfo. La madre (6) dice:

\footnotetext{
este sacó todas las tarjetas amarillas [árbitro], ¡no se van a dejar ganar pues! van por una roja por estar alegando y ese Yepes es el más peleador de todos [y agrega], "voy a comprar el álbum del Mundial sólo para ve a Falcao, Rodríguez y Yepes"... [La madre estrato 2 dice muy alegre: "Vean a Falcao"].
}

A la hora del reality show, el programa preferido es "La Voz Colombia" del Canal Caracol. Además de éste las hijas prefieren "Mundos Opuestos". "La Voz Colombia", en general, llama la atención de los padres cuando termina de cantar el artista y empiezan los jurados a dar su opinión. Las apreciaciones del jurado sirven al Padre (6) para reafirmar la propia, debatir la del jurado o sencillamente para legitimar 
su propia apreciación ante su esposa. Las madres suelen "cantar", seguir en voz alta la interpretación de los artistas, no es raro ver una sonrisa en la cara de las madres cuando están viendo dicho programa. Con relación al reality show "Mundos Opuestos" una madre le comenta a su hija:

"...qué programa [Mundos Opuestos] tan repeye" [malo]... "yo creo [Madre 6], que nosotras somos las únicas que nos vemos este programa, nadie más" [ambas se ríen].

Las series (Telenovelas), también son los programas de preferencia del grupo familiar. Al momento de la observación, "Pablo Escobar el patrón del mal" fue la más vista. Las madres de estrato 6 , hacían comentarios entre las diferencias entre esta serie y "El Capo" de RCN.

[Madre 3 se sienta en su cama para despintarse las uñas, coloca allí el algodón y el removedor, le pregunta a esposo: “¿Ya empezó El Capo?”, (hace zapping buscando esta serie), dice: "primero empezaba a las 9 y son las 9:15 y no ha empezado"].

Otras Telenovelas que frecuentaron las madres, durante el periodo de observación, especialmente las de estratos 1 y 2 , fueron: "El último matrimonio feliz", "Escalera al cielo" y "Abismo de pasión" del canal $\mathrm{RCN}$, además de estas preferencias las madres ven:

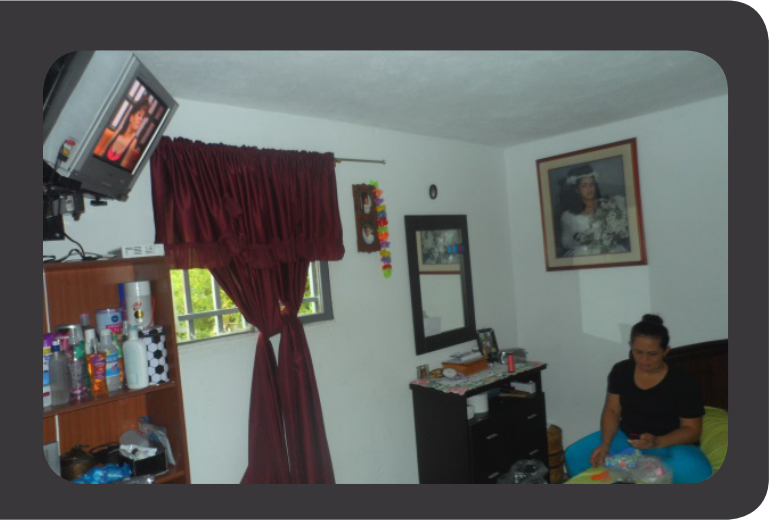

Gitanos, Privace Practice, Séptimo día, fútbol y programas de humor. Los canales que más se visualizan son: Caracol, RCN, NatGeo, Discovery, Super Canal, Teleantioquia, Discovery Channel, History Channel, Film \& Arts, y National Geographic Home \& Health [de este canal el programa "Adolescentes Rebeldes" y "Sala de maternidad"]

El canal regional Teleantioquia, Cosmovisión y el Canal de las Estrellas, son otros canales vistos por las madres, especialmente de estrato 1,2 y 3 . Esto lo hacen generalmente cuando los demás canales entran a comerciales. En Teleantioquia, el programa "El Colectivo" y las noticias son los más vistos. Entre los programas predilectos se encuentran, "El líder de la manada", la novela "Casa de Reinas" del canal $\mathrm{RCN}$, y el programa "Do Re Millones" del Canal Caracol.

[M1, viendo "Do Re Millones”] “¿Será que se gana el carro? ¡Claro que con esa pinta, mejor que no se lo ganó!" [Cambia de canal para el "Canal de las Estrellas"]

Las noticias de Telantioquia, también llaman la atención de las madres.

[En el noticiero, están pasando una nota sobre el concierto de Madonna en Medellín. La madre 3 , hace cometarios acerca de este concierto; en ese momento el presentador Yilmar Gómez, de la sección del entretenimiento de las noticas de
Teleantioquia, habla del apoyo que Madonna hace a las minorías, como las comunidades LGTB y agrega: ¿de la que hacen o hacemos parte? que se incluya él también" (se ríe) [5].

Los programas que se refieren a pérdida de peso, también son los preferidos por las madres. [Madre 3, habla por teléfono con una amiga]:

\begin{abstract}
“...yo aquí viendo eso de un programa, ese dizque "Gorditos de Corazón", de gente que ha rebajado kilos. Será llamar haber pa' que me rebajen 30", [se ríe y agrega] "Yo como soy de incrédula, yo creo que lo mejor pa' uno es cerrar la boca mija"... "yo ahorita estaba viendo, o sea antes de esto [el programa de gorditos] estaban dizque en Gimnasio Fitness, ¡Ay! tan bueno y me acordaba cuando yo iba al gimnasio, tan bueno, a mí me gustaba hacer mucho ejercicio. Uno como se deja de horrible".
\end{abstract}

Le dice también a su amiga que ya no tiene tiempo, que le da pereza ir sola, que antes lo hacía porque ya tenía su rutina pero ahora no puede por sus hijos y sobre todo porque les tiene que ayudar a hacer las tareas. Sigue comentando a la amiga, por el teléfono, sobre el programa Gorditos de Corazón:

“...una señora, que vea, pesaba 119 kilos está en 77, imagínate" [y le repite] "77 o sea que rebajo cuarenta y algo de kilos, mucho, ¿cierto?, "qué pecao" se puso a llorar que porque el marido la había dejado por gorda; jajá! esa fue una de las cosas que más la marcó y la hizo tomar la decisión, porque había tenido que organizar- mija el baño-, lo había tenido que poner más alto para ella entrar...su vida era muy triste, ella se quería morir... [le explica a la amiga en qué consiste la fundación Gorditos de Corazón y agrega] "es que yo digo, la salud no tiene precio", "todo está en la mente, la fuerza de voluntad"... [ le dice a su amiga, los alimentos y bebidas que tienen muchas calorías, y las recomendaciones que hacen en el programa para no subir de peso.

Los estudios de recepción muestran que el televidente resignifica educativamente algunos programas cuando en ellos reconoce problemas o temas significativos para su vida familiar y social, y desde el programa puede explorar formas de encararlos; tal reconocimiento es facilitado cuando este programa es producido con formas testimoniales de personas que han experimentado y enfrentado esos problemas, en lugar de formas formuladas a través de enunciados abstractos y generales (Fuenzalida, 2011).

A las madres, en especial las de estrato 3 , les gustan los programas de humor:

[Madre 3, riendo, llama al hijo y le dice]: "mira Roger, jajajaja como le arrancan esos pelos a ese man todo peludo, aquí todo peludo, con esa cera así y chaque" [hace la acción con su mano, sigue viendo el programa y se ríe.. trata de pronunciar el nombre del programa] "ridiculizaciones, ridicu" [su hijo, desde la puerta del cuarto le dice "ridículos"].

Después de mucho zapping, una madre dice: “...no hay nada más que ver".

El zapping entre noticieros, es habitual entre los padres de estrato 1, 2, 3 y 4, de las noticias del Canal Caracol, se pasa a las de Telemedellín, también a las de RCN y a las del Canal NTN 24. [Veo noticieros] "para enterarme de lo que pasa en el país" [6]. 
Los padres de estrato 1 prefieren las noticias de deportes de Teleantioquia. Otro de los programas visto por estos es "Nuestra semana, nuestra tele", también "El lavadero", programa de farándula, ambos programas son del canal RCN. Ven también, "Mil maneras de morir" del canal Infinito, "Testigo Directo", el programa de humor "The Suso's Show" del canal local Telemedellín, y Serenata de Teleantioquia.

[Padre 4. Se ríe viendo el programa "The Suso's Show"... hace zapping y regresa al programa "Testigo directo", donde están pasando la confesiones de Popeye, uno de los lugartenientes de Pablo Escobar. "También me gustan canales y programas de historia medicina, decoración y cocina"]. [P5] me gustan programas de opinión como 360 grados y películas como las de Film \& Arts. Me gustan los documentales [P3].

El canal Discovery Channel, también es frecuentado por los padres así como el CineMax. Entre los programas preferidos "Construcción" y "Maquinaria pesada".

[Padre estrato 1] comienza a ver la programación que tiene el canal durante el día (servicio que presta la televisión interactiva) y comenta "Aquí es donde dan "El Capo" pero bien tarde. Pasa de canal para "CineMax".. otro día de observación, el padre 1 está viendo una película de acción donde actúa Jean Claude Van Dame; ríe con una escena de la película.

En algunos de sus estudios Morley (1988), encontró que "la atención masculina a la TV tiende a ser más exclusiva y dedicada" Fuenzalida (2012). En la etnografía realizada, se evidenció que la atención masculina a la TV, en el caso de la audiencia de Medellín, no es tan exclusiva y dedicada.

Las hijas, eligen programación de los canales:

Warner Brothers, NatGeo, Canal Caracol, Canal E! , Boomerang, Discovery Home \& Health, RCN, Space, Fox, Sony. Entre los programas que ven están: Friends, The Big Bang Theory, Gente Única, El chico de media tonelada, Private Practice, Bank of Hollywood, Acumuladores, The Amazing Race, The $\mathrm{X}$ Factor, Grey's Anatomy. Ocasionalmente ven fútbol y también noticias, si de noticias económicas se trata, las preferidas son las de Caracol.

Estas ríen a solas con sus programas preferidos, los de bromas y humor. Otro programa que al parecer capta la atención de ellas, es el programa Séptimo día, claro está, que cuando entran a comerciales, hacen zapping, pero siempre retornan a este programa esperando que reinicie la historia.

HA2, una joven de 20 años, madre soltera, mientras está en la cocina haciendo el almuerzo, tiene al lado el portátil en una silla, escucha música. Habla por teléfono fijo sobre "la rumba del fin de semana". Se dirige a su habitación, donde tiene el televisor para darle la sopa a su niño, mientras tanto observa las noticias en el Canal RCN.

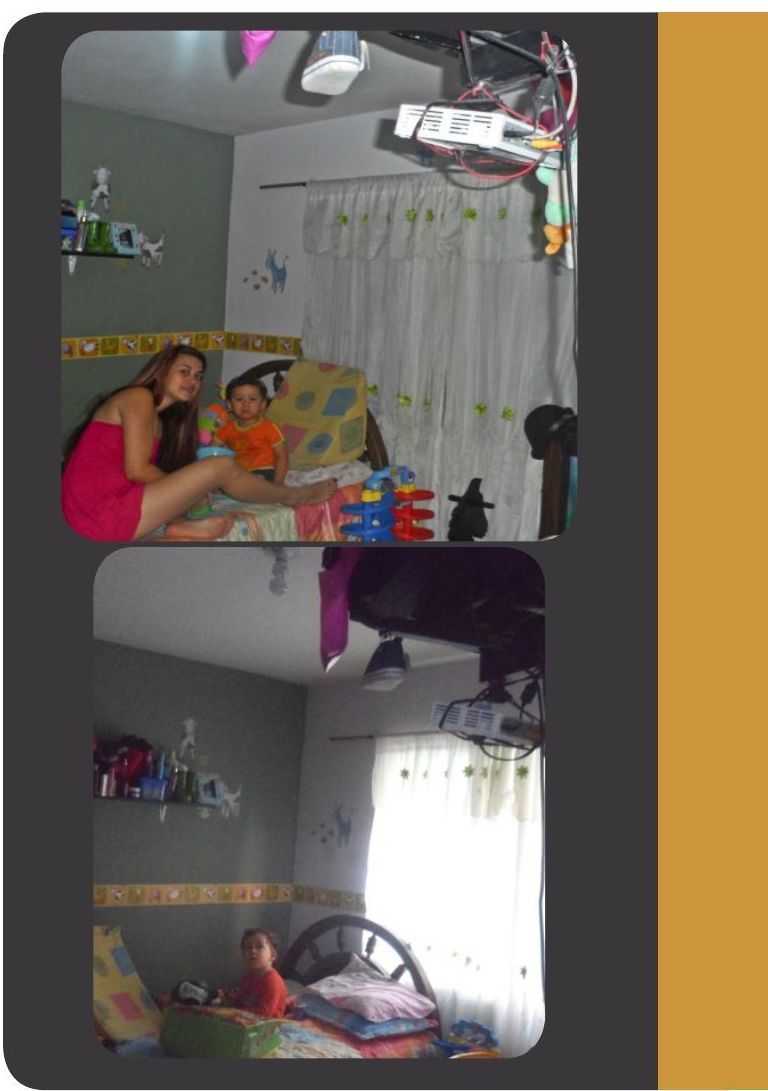

Otro de los usos sociales que aparece en esta etnografía, es el uso de aprendizaje social, que en términos de James Lull, profesor emérito de Estudios de Comunicación en la Universidad Estatal de San José, California, actúa desde la primera infancia, y consiste en que se suelen adoptar modalidades de comportamiento, imitando a ciertos personajes sean reales o de ficción; desde esta perspectiva los medios de comunicación se constituyen en agentes socializadores de ciertos comportamiento.

[La hija, de 6 años, de una familia estrato 1 , frecuenta el Canal Disney, el programa Jungla Sobre Ruedas, entre tanto baila y cantan las canciones del programa, come y también colorea un libro. También ve "Florería de Sofía". Le gusta Disney Channel su programa preferido "Fresita". La niña hace zapping entre el canal Discovery Kids y Disney Junior, de éste último le gusta ver la serie "Olivia, "La colmena feliz" y "Aventuras en Tutti Frutti". La pequeña tiene entre sus hábitos de consumo ver películas, en YouTube, sus predilectas: Barbie y Rapunzel. Esto lo hace mientras juega con el celular de su papá. El padre ingresa a la habitación de su hija, allí también hay un televisor, se acuesta en la cama con ella y comienza a llamarla "Olivia!... Olivia!... Olivia!" como el personaje de la serie que pasa por Disney Junior y que tanto le gusta a su hija].

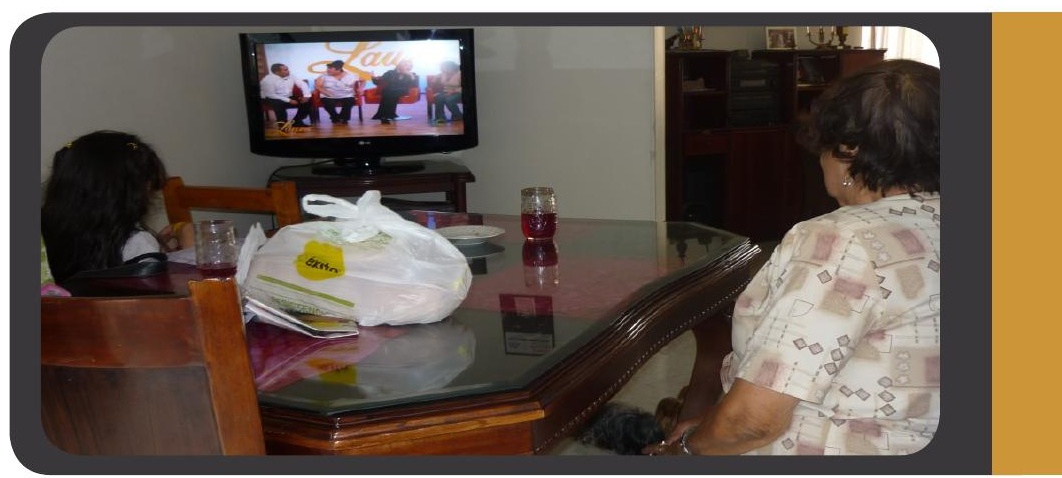

Estos hallazgos coinciden con la apreciación de Fuenzalida (2012), cuando indica que la atención de la TV, sugiere varias tipologías. Collet (1986) encontró que los niños juegan, se mueven e interactúan mientras ven TV, se ríen, se burlan, etc. Barrios (1988) observó que algunos niños ven TV mientras hacen sus tareas escolares, y otros juegan con sus propios juguetes mientras ven TV. 
Para James Lull (1992), entre los usos sociales de la televisión está el uso estructural, que consiste en que en algunas familias, se utiliza la televisión como fondo para su vida cotidiana, en otras palabras la televisión es parte del ambiente familiar, es compañía, especialmente para personas que se encuentran solas en la casa. En este estudio se evidencia este tipo de uso. En cuanto a los diversos usos del artefacto TV en el hogar, se observó que se utiliza como monitor para visualizar, navegar en internet, ver películas en línea, e interaccionar con videojuegos.

En la familia de estrato 1 tanto el computador, como la TV están ubicados en la sala. Allí, la hija de 6 años está viendo una película de la Barbie en YouTube, a su lado se encuentra un primo mirando la película con ella. El TV, se usa también para los videojuegos. Una madre de estrato 3 se va para el cuarto de su hijo a jugar Play Station, es una lucha. Durante el juego ellos conversan, se ríen y gritan.

\subsubsection{TV y algo más}

Los hijos, al igual que sus padres, ven la TV con el celular en la mano, atienden llamadas. Generalmente hablan de temas de trabajo o estudio. También ven la TV alternando esta actividad con la manipulación de la tablet, y en ocasiones con la lectura de revistas, como JetSet. Los padres pasan la vista del TV al libro de turno, que al igual que el celular, está sobre la cama. Finalmente la TV gana la atención al libro, y los padres se centran en la etapa final de la "La Voz Colombia".

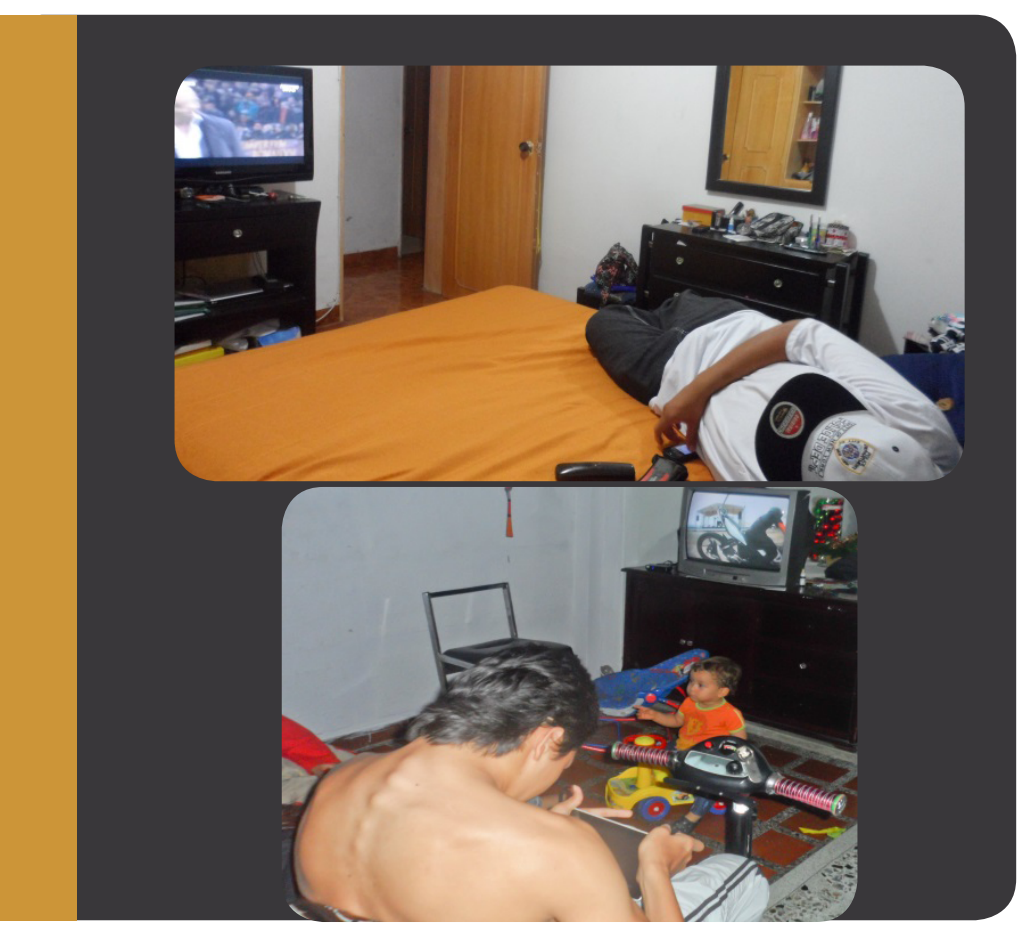

[Hijo de estrato 1]...sale de la habitación principal, se dirige a la sala y se sienta en el computador a jugar video juegos en línea. En el momento el televisor queda encendido en la habitación pero todos se encuentran en la sala dialogando y no interactúan con él.

Mientras se consume televisión todos los miembros de la familia realizan una actividad alterna (están en el computador, cocinan, manipulan dispositivos móviles, realizan tareas, conversan, comen), en especial los adolescentes que tienen otras formas de distracción, por lo que la televisión es una segunda opción.
"Desde pequeño era la televisión prendida y mi hijo con los carritos alrededor" (M16).

\subsection{Entre zapping y zapping, el Spoiler}

El zapping como un particular modo de ver la televisión, es una práctica, una prueba más de la necesidad psicológica de un ritmo trepidante en los programas televisivos, como consecuencia de la modificación de los hábitos perceptivos de las nuevas generaciones" (Ferres, 1994). En la etnografía realizada, se observó que los primeros segundos de los comerciales llaman la atención de los padres, a los que les conceden unos vistazos mientras se leen un libro [P6], o mientras empieza el programa [P4], tampoco falta la dormidita entre los comerciales e incluso durante el partido o el reality show.

Las madres, de estrato 4, 5 y 6 en general, no ven comerciales, cuando éstos aparecen, hacen zapping. Pero si se trata del Spoiler [9] de su telenovela o programa preferido, se quedan viendo y hasta los comentan. "¡Lo matan!, ¡Lo matan!", este caso referido a la serie "Pablo Escobar, el patrón del mal". En cuanto a las hijas, el zapping, es seguro cada que hay comerciales.

HA1, niña de 6 años de estrato 1 , se voltea dándole la espalda al televisor mientras este se encuentra en comerciales [10]. Una joven de estrato 2, ve los comerciales que pasan por la TV que está ubicada en la sala de su casa mientras ella está en la cocina.

Las madres de estrato 1 y 2 , ven comerciales. La madre de estrato 2, se acomoda en el sofá y se concentra en las noticias, pasan el comercial del energizante llamado Maxipower y le dice al novio:

\footnotetext{
“...ese Maxipower, amor, lo venden a $\$ 2.500$ en el Centro".
}

En otro momento de la observación, pasan un comercial de pañales y la madre de estrato (2), comenta sobre una conocida que va a tener un bebé, y habla sobre el tema.

[Alguien pregunta] ¿De dónde es ese Montaner?" [La madre 2, comienza a tomarla del pelo diciendo que es de Urrao, un Municipio de Antioquia, y se ríen. Luego le explica que es de Venezuela. Pasa el Spoiler de la novela "Rafael Orozco, el ídolo" y todos observan en silencio. M2 comenta]: "Cuando yo era novia de él, todavía no tenía ese tipo de problemas" y [hace charlas al respecto]. M2 sigue viendo los comerciales del Canal Caracol, después comenta a su novio "Yo era la mejor televidente en las noches, esperaba hasta media noche para ver esa novela La Traicionera, pero últimamente me quedo dormida".

Finaliza las noticias y la madre (2), toma el control y lo pasa para el canal RCN, en ese momento están en las noticias de deportes, minutos después comienza hacer zapping y lo deja en el canal NatGeo, están en comerciales. La madre de estrato 3, hace zapping cuando se sale a comerciales, también sale del cuarto, regresa después de 2 minutos, se sienta en la cama y coge unas hojas y comienza a leer por 7 minutos, termina de leer y dobla las hojas y las guarda en el nochero, se acomoda en la cama y pasa el canal y luego vuelve a RCN. En otro momento de la observación: 
[La madre de estrato 3] se acuesta en la cama $y$ ve los comerciales atentamente, juega con el control de televisor, luego se reacomoda en la cama mientras comienza la novela, en los comerciales ella está atenta a uno con música y canta parte de la canción en voz más baja, su hija le dice: ¿está llorando? Y ella contesta "ya dejé de llorar" y se ríe.

Pasan un adelanto de la nueva telenovela coreana que pasará por RCN y la Madre 2 dice a su sobrino:

...pero estos están muy feos, eran más lindos los de Escalera al Cielo.... [ se refiere a los actores], y agrega, Escalera al cielo es muy triste "que pecao", "que no lo sepa Song Joo [uno de los personajes de la serie], y continúa " él es, el que la está acariciando, i ay!, ino!...” se limpia las lágrimas y sigue viendo la novela, cuando salen a comerciales, se para de la cama y dice: "se acabó, ¿si ve?".

[M4] Hace zapping por los canales internacionales, se queda por un momento en un canal en el que están hablando de moda, se concentra, suelta el control en la cama y se acomoda. [M3] está sentada en la cama viendo RCN la novela "Abismo de Pasión", ella se muestra muy concentrada viendo la novela, salen a comerciales y hace un zapping, se encuentra un canal donde está sonando música, ella se sonríe y se queda viéndolo, sostiene el control con sus manos y se acomoda en la cama, pasa el canal para $\mathrm{RCN}$, y se devuelve inmediatamente para el otro programa. Está pendiente de que inicie otra vez la novela en $\mathrm{RCN}$, se ríe mientras ve TV, lo pasa otra vez para RCN y ya están presentando "María la del barrio", se para de la cama

Los padres observados también hacen zapping. E Padre 1 se ríe en los comerciales de los humoristas "Tola y Maruja", que hacen de almacenes Flamingo. El Padre 3, cuando el programa sale a comerciales, hace zapping, se queda en Discovery; cuando salen a comerciales lo pasa para NatGeo.

En la relación de la teleaudiencia y los hábitos de uso de la TV, se entienden también aquellos aspectos que expresan una relación más "física" con el televisor, es decir, la propia manipulación del aparato. En esta relación entran los lugares de la casa donde se mira habitualmente TV, los momentos del día u horarios en que esta se consume, la cantidad de horas diarias de exposición frente al aparato, así como si el acto de consumo es individual o si se realiza en compañía de otras personas. En esta etnografía se encuentra como hábitos de uso: El combo: "Celular, Cama y TV'.

\section{CONTEXTOS EN LOS QUE SE VE LA TV. EL COMBO: "CELULAR, CAMA Y TV"}

Para los padres la rutina de ver la TV sucede después de la utilización del computador, en el que realizan asuntos de trabajo, envían el email o revisan Facebook. Los computadores de los padres de estratos 5 y 6 están en la biblioteca, ubicación diferente de la del TV que está en la alcoba matrimonial. Por lo general, los estratos 1, 2 y 3 tienen la TV en la sala del hogar, allí también permanece el computador. Cenan en el comedor con el televisor encendido y conversan sobre lo que le ocurrió a cada uno de los integrantes de la familia durante el día.

[El sobrino del Padre 1, sale de la cocina y se dirige a la sala donde está el Padre 1, éste se quita los audífonos y ambos comienzan a ver y escuchar música de género Vallenato, cantan y se ríen, hablan de vídeos y de artistas...P1 se va a su cuarto a ver una película, mientras sostiene el control en su mano, dice]: "¡Ese no sabe bailar nada!" [Aludiendo a una escena de la película donde están bailando en una fiesta de matrimonio]

El celular se recarga, la mayoría de las veces en el enchufe ubicado en dónde se ve la TV, sea la alcoba o la sala. Las madres ven la TV en la cama, con celular en mano o cerca a la cama; la alternan con el computador, cuando están en el PC el TV permanece prendido, alternan también con las labores del hogar, tal como servir la comida al esposo o los hijos. La TV de la madres está ubicada en la alcoba matrimonial, generalmente ven la TV en la orilla de la cama para tener mayor facilidad de entrar y salir de la alcoba. Si el esposo o los hijos se encuentran en la alcoba matrimonial viendo la TV, rara vez se atiende de inmediato, la sugerencia de la madre cuando dice "cambien de programa", esto se hace cuando se sale a comerciales y en algunos casos no se cambia.

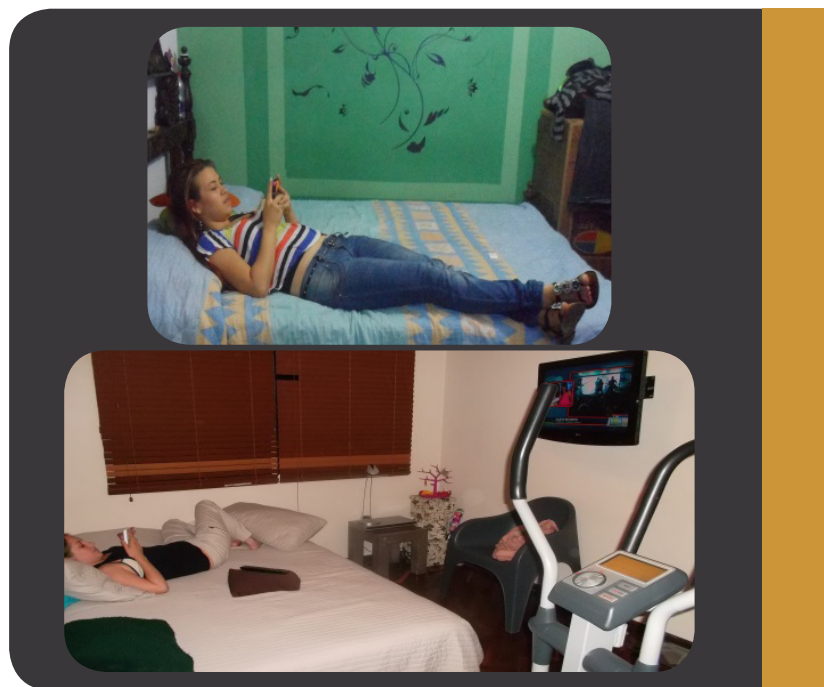

Las hijas [5 y 6] también prefieren ver la TV en la cama, ya sea que estén en sus cuartos o en el de sus padres,en uno de sus lados está el control y en otro el celular. Si están en el cuarto de los padres, las hijas toman el control y hacen zapping.

“¡Ay, no dejaste ver!” dice la madre [6], "es mientras comienza otra vez" [contesta la hija, refiriéndose al programa que estaba viendo la madre]. Entre zapping y zapping la madre debe ver la elección de la hija.

Cada cinco o diez minutos, la hija (6) cambia el canal. Su madre (6) le dice "pero usted tiene ese dedo alborotado". Las hijas ven dos programas a la vez, mientras chatean, ojean una revista, conversan con los padres, revisan las llamadas y mensajes del celular, y hablan por el teléfono fijo o por el celular.

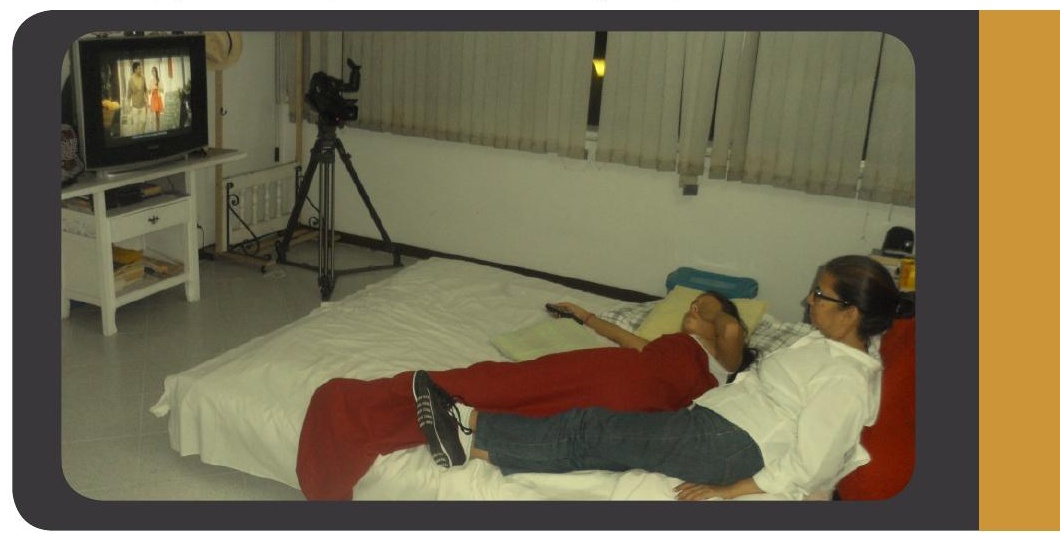

HA6, recibe una llamada al celular y se molesta dice “¿Cómo consiguieron mi número?" [Solicita que por favor la retiren de su base de datos, no le interesan las ofertas de rumba que le están ofreciendo, cuelga la llamada y habla del tema 
con su madre. Continúan viendo el programa el canal sale a comerciales y pasan un avance de otro programa del canal. Pregunta a su madre sobre la llamada que recibió] "¿Uno no puede demandar eso?" su madre le dice "No, seguramente firmaste algo en algún lado, diste tus datos y ya nada que hacer".

Es habitual, que las hijas e hijos se paren con frecuencia, cuando están frente a la TV.

\begin{abstract}
H5 [va para la cocina y saca una Coca Cola, vuelve al cuarto, se acomoda en la cama y sigue interactuando con su celular, va a la biblioteca utiliza el computador, lo apaga, camina, saca de su bolso otro portátil y lo enciende, busca el cargador lo conecta a la energía, lo deja conectado y se va para el cuarto, suena el teléfono, le baja el volumen al TV, habla sobre asuntos de trabajo, cuelga la llamada, ve la TV de pie, sale del cuarto y vuelve a la biblioteca, va por su bolso al comedor, saca el celular, hace una llamada, habla sobre asuntos de trabajo, regresa al cuarto, hace zapping y se queda viendo TV, vuelve y se levanta...]
\end{abstract}

La TV siempre está encendida, cuando están, "encerradas en sus cuartos". Cuando salen, van al cuarto de sus padres, les cambian el programa, hacen comentarios de los programas, hablan de la Universidad o asuntos familiares y nuevamente regresan a sus cuartos, se acomodan junto al computador y mientras hacen sus trabajos de clase, "escuchan" la TV, o simplemente la mantienen prendida a bajo volumen.

[Hijo estrato 2], interactúa en el computado portátil, revisa su correo, abre Facebook. [Hijo estrato 1], agarra el control y abre el menú del paquete interactivo, mira la programación del día y dice: "esta me la voy a ver, esta también" [termina de revisar el menú, lo cierra y descarga el control del televisor en el nochero y sigue viendo la película mientras va almorzando]

\subsection{Usos del consumo de TV}

Lull (1992) plantea que entre los usos sociales de la TV, también está presente el uso relacional, el cual consiste, en que ésta proporciona un marco de referencia común que se emplea para el intercambio de mensajes en la familia, en otras palabras, es una fuente para varios temas de conversación familiar. También se define este uso, en términos de una comunicación cómplice, que alude a proporcionar entretenimiento al consumidor en compañía de otras personas.

En la Etnografía de la Teleaudiencia de Medellín se evidencia el uso relacional de la TV; otro de los elementos que componen el ritual de ver la TV es la conversación. Los padres suelen conversar con sus esposas o hijos de los programas. Ellos conversan sobre Fútbol, se ríen, relacionan temas o personajes del reality show con situaciones o personas que conocen. Solo una visita o una llamada aleja a los padres de la comodidad de la cama, la conversación y la TV. Las madres también hacen comentarios, por ejemplo, cuando en Home\&Health se está pasando un programa de mujeres embarazadas, hablan sobre bebés. Viendo el programa "Acumuladores" una madre dice "tiene hasta diamantes", para referirse a las joyas que guardaba la acumuladora.

\subsubsection{Conversar}

En la ocasión en que se pasaba el programa "Gente Única", la madre (6) hizo referencia a un "muchacho que tiene un problema de enanismo" como el que se mostraba en el programa".

[En el programa se comenta que el personaje a pesar de su discapacidad debe de continuar pagando sus estudios de informática, esto provoca una reacción en la hija (6) quien expresa "Ahhh" y le dice a su madre [quien es docente de informática y de estatura baja] "¿Sí ve? La informática es para discapacitados". La madre se fastidia por el comentario y dice "usted si es más cruel que yo".

En el estudio Televisión y Familia. Una experiencia etnográfica en la vida de tres hogares colimenses (Bautista, Covarrubia y Uribe en Lameiras \& Galindo, 1994, p.111), se evidenció que uno de los usos inconscientes que se hace de la TV es el de la descalificación, ridiculización de algún integrante de la familia. En otras palabras:

\begin{abstract}
"...Se aprovecha la imagen o los discursos de la TV para dar "golpes bajos" dentro del contexto familiar, pues se trata de una descalificación de alguien ante los demás".
\end{abstract}

Este uso se evidencia en la etnografía de Medellín, queda por constatar si se hace de manera inconsciente como se supone o es abierto y consciente.

Siguiendo con los comentarios, se encuentra que las madres, observadas, también opinan sobre los actores "...ese aparece también en "Friends..."; hablan sobre la universidad de sus hijos. Por momentos alternan la TV con la lectura del periódico o de alguna revista, cuyos temas también son objeto de conversación. Esta vez la nota sobre "vacaciones recreativas" que está publicada en el periódico es el tema de conversación de la Madre (6) con su hija.

El padre de estrato 1, su hija y su sobrino comentan sobre la película que están viendo, el padre le dice a la hija "[la película]... trata de unos perros que hablan y de los comportamientos que hacen como si fueran humanos". Ellos hablan también de las actrices que aparecen en la película y que antes han estado en otras producciones.

El hijo de esta familia ve el programa "Domador de caballos" e inicia una conversación con su madre relacionada con este tema: ¿Cuánto puede costar un caballo de esos más o menos?, [su madre le contesta y hablan un momento sobre el tema [11].

[Padre 1] se sienta en la cama a almorzar mientras ve una película en Cine Canal, se ríen de lo que va pasando en la película, su hijo [1] le dice: "ya me la vi", y comienza a contar todo lo que pasa en la película, se ríen.

La comunicación temática [12] también se evidencia en el consumo televisivo que hacen los medellinenses.

La madre de estrato 1 le pregunta a su hija de 6 años acerca de los personajes y sus características, le pregunta también sobre las situaciones en la que se encuentran los personajes. En el programa que ven hacen preguntas al espectador, interactuando así con ellos. La madre repite la pregunta a su hija y esta responde. 
Una conversación de esposos [estrato 1]:

[Madre 1. Entra a la habitación y pregunta] ¿No ha empezado Laura? [Laura en América]. [Padre 1 responde] "No ha empezado todavía" [pasa de canal para RCN y dice] "¡Ah vea ya empezó!" [Los dos se quedan viendo el programa].

[Madre 1, se maquilla mientras escucha la TV y le comenta a su esposo, acerca de los personajes que están en el programa de Laura] "¿Ese Cristian es el esposo de ella? ¡Tan jovencito!". [Padre 1, dice] "para ese gurre de vieja". [Madre 1, se queda mirando el programa y se ríe con los comentarios que "Laura" hace sobre "La Belleza".

[Madre 1. Ingresa nuevamente a la habitación y le dice a Padre 1]: ¿Me quitaste a Laura? [Se sienta en la cama con unos hilos y una bolsa con vestidos de baño, Padre 1, le contesta] “iAh vea pues!", [Pasa nuevamente para RCN al programa de Laura, el que quiere ver su esposa]. [La Madre1, le pregunta a Padre 1 por el tema y él la pone al tanto... le suena el celular y Madre 1, sale corriendo a contestar, regresa de nuevo a la habitación, se sienta a seguir organizando los vestidos de baño mientras habla por el celular sobre el accidente que tuvo su hermana y de la incapacidad que le dieron. [Padre 1, le pregunta por la llamada, Madre 1, no le contesta. Cuelga la llamada y se queda revisando el celular, mientras tanto en la TV sigue "Laura en América"] [13]

Los comentarios sobre las noticias también son habituales.

[Noticiero; en ese momento el tema es Nicaragua que ya ejerce soberanía sobre el meridiano colombiano. Madre 2, comenta con su novio] "Eso es para un problema, metieron ya soberanía cuando no se usa"..

[Comienzan las noticias del entretenimiento] M2, escucha una noticia sobre el salsero Marc Antony y dice "Papasito", se para, va a la cocina por el celular, regresa y le toma una foto, escucha una noticia sobre el presidente Juan Manuel Santos y pregunta "¿Qué fue lo que dijo Santos?" y el novio la pone al tanto...

Pasan una noticia sobre Madonna y M2, le dice a su novio "Los evangélicos dicen que eso de Madonna es un culto al diablo, jah! verdad que usted es evangélico, y se ríe. [Siguen viendo noticias, el novio comenta la noticia de los alumbrados en Medellín, M2, le dice:] "! Ah! qué bonito, hoy era el día para ir a verlos" [hablan sobre el tiempo en el que estarán encendidos los alumbrados, y vuelven al tema de Madonna, de las fotos y montajes que están circulando en Facebook]

En otro momento de la observación, la madre 3, mientras su esposo le comenta asuntos del trabajo, ella observa de reojo la TV, de pronto interrumpe al esposo y hace un comentario de lo que está pasando la TV:

"...mira a este con ese pelicano encima, jajaja" [mientras se ríe le muestra a su esposo lo que está viendo en la televisión], "apenas le coja la nariz" ambos hablan del tema y se ríen.

El padre de estrato 1, no retoma la conversación que traía. Sino que toma el control y le sube volumen al televisor, y le hace un comentario a su esposa, acerca de la mujer que muestran en la pantalla: "Esta se llama Bella, pero de bella no tiene nada esa viejita", hace zapping pasa por los canales FOX, FX, ID. Otro día de observación, los comentarios son para el equipo de veteranos de Rugby de Antioquia, que se enfrentó con un equipo Francés en Medellín, la transmisión la hizo Teleantioquia.

[Dice Padre 1] "Están gordos y veteranos", [En los comerciales, aprovecha y saca la ropa de trabajo de su closet y sale al baño]

Padre e hijo de estrato 3, comentan sobre fútbol, ambos gritan "Goool", se acaba el primer tiempo. P3 hace zapping por los demás canales y vuelve a Caracol.

[Padre estrato 3] con voz más fuerte: "Camilo, ¿cómo fue que quedó el partido Millonarios - Gremio allá en Brasil?".

En otro día de observación, la hija $(\mathrm{H} 2)$, estrato 2 , desde la puerta del baño de su casa, sale a ver la noticia sobre la novia del futbolista Radamel Falcao García, se para en la sala, donde está el televisor, se queda observando la noticia de una pareja de un extranjero, comenta:

"yo siempre quise tener un marido extranjero" [se va para la cocina... vuelve y escucha la noticia de una rectora que va a organizar los grados de los estudiantes por ventanilla porque descubrió un supuesto fraude, dice] "Que estupidez" [se va para la cocina y desde allí sigue las noticias...]

Comentarios acerca de la telenovela "Pablo Escobar, el patrón del mal":

[Padre 3] “...ahí se le ve el montaje cuando lo toman de lado", [la madre le responde] ¿sí?, él responde "mirá, mirá". [Padre 3] "...puso a esa vieja a que se comiera el hijo". La madre dice: "quién es ese, jah!, ese fue el que le explotó la bomba". [Hijo] "¿ese es el hermano de Pablo?" [Madre 3] "no, es el primo".

"El último matrimonio feliz" es comentado entre amigas. [Madre 3, está al teléfono, conversando con una amiga, habla de la serie "El último matrimonio feliz", también comentan del programa Escalera al cielo, le dice a su amiga]:

“... ¿si se vio Escalera al cielo?, jay, qué pesar! ¿Cierto?...ya él [protagonista] por lo menos sabe que ella va a quedar ciega"..."yo creo que cuando le vaya a ver el final a eso [La novela] voy a llorar mucho"... "nos invaden los coreanos [Telenovelas coreanas] pero son buenas y si son así de corticas muy buenas". [Luego habla de la novela "La Traicionera", que ya está muy larga].

[Madre 3, comenta con su esposo la telenovela "Escalera al cielo"] dice: "a mí, me han dicho que me la vea por internet [la telenovela] sino que...o sea... yo la puedo buscar en internet y ver el final, pero ¿por qué?, si yo la sigo viendo ahí [TV], no me quiero adelantar ni nada.

La hija 2, se dirige a la habitación de su madre, se organiza el cabello y se maquilla, vuelve y revisa su celular. Habla en voz alta como conversando con su pequeño hijo, comenta la noticia de que la cantante Madonna estará de gira por Medellín.

“...esa vieja [Madonna] está muy exigente dicen que cuando ella se vaya tienen que hace una limpieza, porque no quiere que se quede $n$ un cabello de ella" [en Medellín]. [HA 2. Canta la canción de Madonna - Music] "JסS.'Music

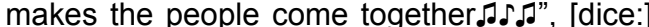
"¡Verdad que tengo que montar el arroz! [Suelta el celular y se dirige a la cocina] 
En estos contextos y rituales en los que sucede el consumo de la TV, el teléfono fijo aparece más frecuentemente en el estrato 1 y 2 [14]. El celular [15] se encuentra en todos los estratos. En esta observación las revistas adjuntas al periódico, son las que más se visibilizan, el periódico en su formato general, no. Algunas de las madres de estrato 1, ven la TV mientras leen el periódico Q'hubo. El computador aparece como un elemento más de hogar. En la biblioteca y en cada alcoba en el caso de las familias de estratos 5 y 6 .

"Las investigaciones sobre las conductas y comportamientos de los consumidores del medio televisivo reformulan el concepto de audiencia, a partir de las acciones y relaciones sociales que acompañan el visionado televisivo. El término audiencia activa (Callejo, 1995) define, por tanto, la conducta y acciones de los usuarios de los medios que se han ido conformando en hábitos cotidianos de los consumidores mediante el proceso de recepción televisiva. El espacio familiar, el hogar, continua siendo el lugar privilegiado de uso televisivo. Televisión y familia comparten un mismo espacio, por lo que el consumo de las emisiones televisivas se asienta sobre las propias relaciones familiares" [16]

\subsection{No todo es TV.}

\subsection{1 "No nos tiene amarrados"}

Las familias observadas, en sus ratos libres salen al Parque Explora, el Jardín Botánico, a comer, van al cine, se reúnen con amigos, van a la finca, visitan los suegros, los abuelos, y los domingos ven televisión juntos. En semana, la tarde - noche es el horario habitual para "ver" la TV. Indican que no los tiene "amarrados", no esperan, ni siguen programas, y que no les marca sus rutinas, el Padre de estrato 5 dice:

"No me cuesta ningún efecto perderme algún programa... El Capo fue el que me determinó por algunos meses, la hora de sentarse a ver la TV". Padre 4, "solo me marca la rutina diaria la TV cuando hay partidos. Trato de ajustar mi horario y llego a tiempo para verlo".

Martín Serrano: 1981, p46, en sus análisis de la TV encontró que en la mayoría de los casos el comportamiento de los sujetos estaba determinado por la programación de la televisión. Los ritmos de trabajo, tiempo de alimentación, así como la vida fuera del contexto familiar. En el caso de este estudio, se encuentra que es baja la influencia que la televisión tiene en la organización de la vida familiar.

En general, las rutinas de los padres observados consisten en "ver la TV" mientras ayudan a sus esposas en los quehaceres domésticos, esta rutina se establece de acuerdo con los horarios de trabajo de cada uno de ellos, especialmente en estrato 1,2 y 3 . En los estratos 4 y 5 , ven televisión los fines de semana, cuando van a la finca.

[P5] Me levanto temprano, escucho noticias leo la prensa, trabajo en el computador escribo artículos, leo. Veo televisión como entretenimiento, he ido dejando "el vicio", he ido perdiendo el interés. [P6] Preparo e desayuno, llevo a mis hijos a la universidad voy a trabajar, hago cursos de rehabilitación pinto, preparo clases, califico exámenes. [P1] En mis ratos libres veo televisión o me voy por ahí a "andar". [P4] Estoy con mi familia. Más que todo los fines de semana veo TV. [P1] trabaja de celador en una unidad residencial y dice: "veo también la TV en el trabajo [agrega con picardía] "trabajo mucho con los ojos; especialmente en las horas de la tarde".

La TV se ve en compañía, los padres con las esposas y los hijos, algunas veces con los amigos. Es común que los hijos hombres consuman TV solos. Estos además ayudan con las labores domésticas, estudian, salen con los amigos, juegan XBOX, fútbol, esto dependiendo de sus horarios de estudio o trabajo.

"[HO1] Me levanto, desayuno, ayudo en la casa, en la tarde cuando llego del colegio, veo televisión. Voy a hacer deporte, a la iglesia salgo con el grupo de cantantes de reggaetón, estoy en el computador. [HO2] Me levanto temprano para ir a la universidad, en la tarde veo partidos de fútbol, juego XBOX, estudio estoy en Facebook y salgo con mis amigos. [HOG3] Estudio, estoy en la casa, escucho música y salgo con mis amigos. [HO6] Voy a cine, a teatro, salgo con amigos. [HO4] Vendo zapatos, juego al fútbol, hablo por Facebook juego con el XBOX, leo, salgo con mi mamá.

\subsection{TV para los "desparchados"}

Las hijas e hijos, manifiestan dedicarle tiempo a la TV cuando están "desparchados", esto es cuando no tienen otra cosa qué hacer. Cuando queremos descansar "ponemos el televisor para que nos arrulle" [17]. Los horarios más frecuentes en los que consumen televisión son de lunes a viernes desde las 7:30 de la noche, cuando todos los miembros de la familia están en la vivienda, hasta las 10:30 de la noche, hora a partir de la cual el TV permanece encendido, sin manipulación hasta las 12:00 de la noche, horario en el que por lo general se acuestan a dormir. Los sábados en la mañana, es usual que madres o hijas coloquen canales musicales mientras hace las labores de la casa y los domingos, la familia ve películas que baja desde internet.

\section{CONCLUSIONES}

El consumo de las emisiones televisivas de los medellinenses se asienta sobre las propias relaciones familiares. En términos generales presenta un consumo cómplice de la TV, esto es que les gusta ver la TV en compañía con otras personas (hijas, hijos, empleadas del hogar, esposos, etc.). Los hijos hombres de estrato 5 y 6 prefieren consumir la TV de manera individual. Las madres de estrato 4, 5 y 6 en general, hacen zapping durante los comerciales. Las de estrato 1 y 2 lo hacen ocasionalmente y hasta los comentan. Los padres suelen conversan con sus esposas o hijos de los programas que están viendo en la TV. Los temas relacionados con el consumo televisivo, tienen más prioridad, que los temas de trabajo, estudio o asuntos personales, los cuales tienen cabida si tienen alguna relación o referencia con lo que se presenta en ese momento en la TV.

Como expresa Neil Postman "no vemos la realidad como es, sino como son nuestros lenguajes", la televisión sería uno de dichos lenguajes; en tal sentido, los medios serían nuestras metáforas, en tanto crean el contenido de nuestra cultura. La pregunta que queda es ¿Qué tipo de cultura, de conversación con el otro se le sugiere a los Medellinenses desde la TV? 
Los jóvenes de Medellín, se muestran más interesados que en otros tiempos por las noticias económicas. Se observa cómo las madres utilizan la TV como medio de aprendizaje de sus hijos más pequeños, al preguntarles por personajes, por las temáticas, etc., como tratando que de alguna manera ejerciten la memoria, la argumentación, etc.

En los estratos sociales 4, 5 y 6, se observa, que el consumo de televisión se hace simultáneamente con el de medios impresos, como revistas especializadas o de farándula, periódicos y libros. En general en todos los estratos se hace con medios como el celular. No se presentó que se utilizara internet o celular para complementar o interactuar con contenidos propuestos desde la TV, ni siquiera en el caso específico de los realitys shows. Se sabe que dichas interacciones se constituyen en una tendencia, aunque en este estudio no se evidenció de manera puntual.

En los estratos 4, 5 y 6 , el lugar preferido para el consumo de la TV son las habitaciones. En los estratos 1, 2 y 3 son la sala o el comedor. En todos los estratos, antes de ver la TV hay que asegurarse de tener el celular a la mano.

El zapping, entre comerciales sigue siendo habitual, sin embargo, aparece como tendencia que cuando se pasa un spoiler, esto es, un adelanto de una telenovela, noticiero, etc., se detiene el zapping. Al parecer, el spoiler permite estar enterado de algo que probablemente no se pueda ver o seguir, una serie o noticias. Se prefiere ver a "pincelazos" y quedar al tanto del asunto.

El uso de la televisión como fondo de la vida cotidiana, también es habitual en la teleaudiencia de Medellín, "Nadie ve TV", sencillamente está allí mientras se hacen otras acciones. Se evidencia también, en estratos 1,2 , y 3 , que la televisión es prepaga, es decir, por semanas, días, etc. Servicio que brinda DirecTV; la cual es diferente a los planes de hogar que tienen un pago mensual, como UNE. Todos los estratos consumen canales y programación internacional.

Los padres presentan una tendencia a ver programas de farándula, los cuales se suponía, eran preferidos por las mujeres. Les gusta el programa el "El lavadero" del canal RCN. También les gustan canales y programas de historia, medicina, decoración y cocina.

En general el futbol, el humor y las telenovelas, son los programas preferidos por la teleaudiencia de Medellín. El uso consciente de la TV, continúa estableciéndose como agente de compañía, agente consejero, medio que da motivo de conversación, medio de entretenimiento y distracción, medio que permite tomar decisiones. Se presenta una variación en cuanto a regulación del tiempo o de rutinas que anteriormente se determinaban por la programación de la TV. Entre los usos inconscientes se encuentra que son los hijos, quienes determinan que programa se ve o no, a diferencia de estudios anteriores en los que se observaba que los padres determinaban a sus hijos más pequeños qué programa ver y a qué hora. Se observa una alta tendencia a la utilización de los contenidos de la TV para la descalificación, ridiculización de algún miembro de la familia. El uso del medio como catarsis, se evidencia notablemente, en especial, en las madres de familia de estrato 1,2 y 3.
La teleaudiencia de Medellín, hace comparaciones entre programas, canales. Comenta sobre la producción de los programas. Les gusta que la programación se cumpla tal como se ha ofrecido. Se presenta la tendencia de "ver" programas que se refieran a la pérdida de peso. Las madres de estrato 1,2 y 3 prefieren seguir "sus telenovelas", según se van presentando en el canal y no adelantarse los capítulos por internet. Les gustan las telenovelas cortas. Al parecer no hay una "fidelidad" por canal o programa, sencillamente se busca en el menú.

En Medellín la televisión no es el centro de atracción de la vida familiar, está en el hogar, se le escucha, sin mucha atención, se comparte su atención con otros medios.

\section{BIBLIOGRAFÍA}

- AHUMADA, Rafael. T.V Su Influencia en la Percepción de la Realidad Social. Universidad Autónoma Metropolitana. 2010.

- APARICIO, Calero Fernando. Modalidades actuales y perspectivas del servicio de televisión en Colombia. Disponible en: http://www.comminit. com/la/node/149841 [noviembre 9 de 2011].

- BARRIOS, L. (1988). Television, Telenovelas, and Family Life in Venezuela. En: Lull J. (ed). World Family Watch Television. Sage.

- BAUTISTA, Angélica; COVARRUBIA, Karla; URIBE, Ana. Televisión y familia, una experiencia etnográfica en la vida de tres hogares colimenses. En: GALINDO Cáceres, Jesús \& LAMEIRAS José. Medios y mediaciones. México. Colegio de Michoacan-ITESO, 1994. p 101-127.

- BONILLA, Jorge Iván. Re-visitando los estudios de recepción/audiencias en Colombia. En Comunicación y Sociedad: Departamento de Estudios de la Comunicación Social Universidad de Guadalajara [en línea] $\mathrm{N}^{\circ} 16$ (julio - diciembre, 2011). Disponible en: http:// www.comunicacionysociedad.cucsh.udg.mx/pdf/ cys16_11/3bonilla.pdf [septiembre 20 de 2011].

- CARRASCO, Jorge. Cine y Televisión Digital Manual Técnico. Universidad de Barcelona.2010.

- CHAVERO, Haydee; GARCÍA, Núria. Los hábitos del consumo televisivo de una comunidad extranjera:elcasodeestudianteslatinoamericanos en Barcelona. En: EUSKAMPUS: Universidad del país Vasco [en línea]. Vol 10, No 19 (2005). Disponible en: http://www.ehu.es/ojs/index.php/ Zer/article/view/3852 [19 de octubre 2011] ISSN 1137-1102.

- FERRES, Joan. Televisión y educación. Barcelona: Editorial Paidós, 1994.

- FORTUNY, i Batalla, Jordi \& Solá, Clara (2012). El futur de la televisió a l'espai catalá de comunicació. Fundació Escacc.

- FUENZALIDA, Valerio (2012). Procesos de la audiencia ante la tv. Diálogos de la Comunicación. Revista Académica de la Federación Latinoamericana de Facultades de Comunicación Social. Edición N85. 
- FUENZALIDA, V. (2010). Educación para la comunicación televisiva. Recuperado de: http:// www.cntv.cl/prontus_cntv/site/artic/20120410/ asocfile/20120410190800/art culovalerio fuenzalida_2_mayo_2010_.pdf.

- FUENZALIDA V. (2011). Resignificación de la educación televisiva: desde la escuela a la vida cotidiana. Una visión desde América Latina. Comunicar. (36), XVIII, pp. 15-23.

- FRANKENBERG, Lorena; LOZANO, José Carlos \& varios. Enfoques teóricos y estrategias metodológicas en la investigación empírica de audiencias televisivas en América Latina: 1992 - 2007. En Comunicación y Sociedad: Departamento de Estudios de la Comunicación Social Universidad de Guadalajara [en línea]. $\mathrm{N}^{\circ} 010$ (Julio-diciembre, 2008). Disponible en: http://redalyc.uaemex.mx/pdf/346/34601004.pdf [septiembre 27 de 2011].

- GARCÍA, Muñoz Nuria. Comportamientos y hábitos de consumo televisivo del niño en el ámbito familiar. Ballaterra, 1996. Tesis doctoral. Disponible en http://tdx.cat/bitstream/handle/10803/4154/ TNGM3de3.pdf?sequence $=3$.

- GOETZ, J. P; LeCompte Margaret Diane. Etnografía y diseño cualitativo en investigación educativa. Madrid: Ediciones Morata, S.A.S, 1988. p 281.

- GUBER, Rosana. La etnografía: método, campo y reflexividad. Enciclopedia Latinoamericana de Sociocultura y Comunicación. Bogotá: Grupo Editorial Norma, 2001. p 146.

- GONZÁLEZ, José Fernando; RUÍZ, Elvia y Otros (2012). Formación de teleaudiencias críticas juveniles: Interlocución, la mejor retroalimentación. Revista Virtual Luciérnaga, Año 4, N7. Grupo de Investigación en Comunicación, Facultad de Comunicación Audiovisual, Politécnico Colombiano Jaime Isaza Cadavid. Medellín- Colombia. ISSN 2017-1557. Págs. 1- 11. Disponible en http://politecnicojic.edu.co/ luciernaga7/pdf/1_formacion_de_teleaudiencias. pdf.

- JENSEN, Klaus: Qualitative Audience Research: towards an integrative approach to reception. En Cristical Studies in Mass Communication. Vol $4 \mathrm{~N}$ 1. SCA (1987). Estados Unidos.

- JENSEN, Klaus \& K.E. ROSENGREN: Five Tradition in Searach of the Audience. En European Journal pof Communication. Vol 5. N2-3 Sage Publications (1990). Londres.

- LAMEIRAS, José \& GALINDO, Jesús (1994). Medios y Mediaciones. Colegio de MichoacanITESO.

- LULL, James. "Los usos sociales de la televisión" [en línea]. Disponible en: http://www.jameslull. com/losusos.html [octubre 19 de 2011]

- OROZCO, Gómez Guillermo (2001). Televisión, audiencias y educación. Enciclopedia Latinoamericana de Sociocultura y Comunicación. Grupo editorial Norma, 2001. p 82.

- OROZCO, G. (1996). Televisión y audiencias. Un enfoque cualitativo. Madrid: Ediciones de la Torre.

- OROZCO, Gómez. Guillermo. La investigación en comunicación desde la perspectiva cualitativa, Capítulo III. Capítulo VII. Universidad Nacional de La Plata, Facultad de Periodismo y Comunicación Social. Guadalajara, Jalisco, 2000, p. 51-66; 129151.

- OROzCO, Guillermo. Revista de Ciencias Sociales en su artículo ¿Cómo "consumen" televisión los escolares?

- OROZCO, Guillermo (2000). La Investigación en Comunicación desde la Perspectiva Cualitativa. Guadalajara, Jalisco.

- RUIZ, M. Elvia; LópezA. Claudia; Escobar, C. Juan (2011). LOS JÓVENES, EL IDEAL ESTÉTICO Y LA TELEVISIÓN: "El cuerpo real y el imaginado". Grupo de Investigación en Comunicación del Politécnico Colombiano Jaime Isaza Cadavid. Medellín - Colombia. Año III, Número 6, ISSN 2017-1557. Disponible en: http://politecnicojic. edu.co/luciernaga6/pdf/jovenes_ideas_estetico_ tv.pdf.

- RUíz, Elvia. Los Imaginarios de la Cultura Somática que Construyen los Jóvenes Escolarizados de Medellín, a partir de las Representaciones que Transmite la TV que Ellos Consumen. Universidad de Antioquia. Politécnico Jaime Isaza Cadavid. 2009.

- MORLEY, David. Televisión, audiencias y estudios culturales. Buenos Aires. Amorrortu Editores, 1996.

- MURILLO, Javier; MARTINEZ Chyntia. INVESTIGACIÓN ETNOGRÁFICA. Métodos de Investigación Educativa en Ed. Especial [en línea]. Disponible en: http://www.uam.es/personal_pdi/ stmaria/jmurillo/InvestigacionEE/Presentaciones/ Curso_10/I_Etnografica_Trabajo.pdf [octubre 19 de 2011].

- NIGHTINGALE, Virginia (2011).The Handbook of Media Audiences. Series Editor: Annabelle Sreberny (School of Oriental and African Studies, London). This edition first published.

- RODRÍGUEZ, A. (2012). Los niños menores de tres años y la televisión. Perspectivas de investigación y debate (1999-2010). Bogotá: Ministerio de Cultura. Revista Luciérnaga Año 4, N7. Grupo de Investigación en Comunicación, Facultad de Comunicación Audiovisual, Politécnico Colombiano Jaime Isaza Cadavid. Medellín-Colombia. ISSN 2017-1557. Págs. 1222. Disponible en http://politecnicojic.edu.co/ luciernaga7/pdf/2_ninos_menores_3_anos_.pdf.

- SÁNCHEZ Vilela R. (2000). Sueños Cotidianos. Telenovela y Oralidad. Montevideo: Taurus-U. Católica.

- SANTAGADA, Miguel Ángel. Los estudios de comunicación y la etnografía de audiencias. En: Revista Latina de Comunicación Social [en línea]. №10. (Octubre de 1998). ISSN 1138-5820.

- SGAMMINI, Marcela. Televisión por cable: hábitos de consumo y tipologías. Escuela de Ciencias de 
la Información. Universidad Nacional de Córdoba. Disponible en: http://www.toposytropos.com.ar/ N6/tesis/sgammini.htm.

- VALLE, F. Mónica (2012). Medios alternativos de Medellín [1]: Recuento Histórico 1987-2006. Revista Virtual Luciérnaga, Año 4, N7. Grupo de Investigación en Comunicación, Facultad de Comunicación Audiovisual, Politécnico Colombiano Jaime Isaza Cadavid. MedellínColombia. ISSN 2027-1557. Págs. 36-46. Disponible en: http://politecnicojic.edu.co/ luciernaga7/pdf/4 medios alternativos.pdf.

- VALLE, F. Mónica (2012). Medios alternativos de Medellín[2]:Diagnóstico2005-2006. RevistaVirtual Luciérnaga, Año 4, N8. Grupo de Investigación en Comunicación, Facultad de Comunicación Audiovisual, Politécnico Colombiano Jaime Isaza Cadavid. Medellín- Colombia. ISSN 2027-1557. Págs. 51-57. Disponible en: http://politecnicojic. edu.co/luciernaga8/pdf/medios-alternativos.pdf.

NOTAS

[1] Revista de Ciencias Sociales en su artículo ¿Cómo "consumen" televisión los escolares?

[2] Citado por CASTELLS, Manuel. La era de la información, la sociedad red, Vol. 1. Siglo XXI Editores, primera edición en español, Madrid, 1999. 590 pp. Pág. 360.

[3] La metodología desarrollada en este estudio se presentará de manera detallada en otro de los artículos productos de este estudio.

\section{[4] Familias de estrato 1, 2, 3, 4, 5 y 6 de Medellín.}

[5] Dando a entender que el presentador pertenecía a dicha comunidad. Observación. 28/11/2012, en la noche, sala de la casa.

[6] P16.

[7] Sgammini, Marcela. Televisión por cable: hábitos de consumo y tipologías. Escuela de Ciencias de la Información. Disponible en http://www.toposytropos. com.ar/N6/tesis/sgammini.htm

\section{[8] Bauman, Zygmunt (2005).}

[9] Spoiler. "Se llama espóiler a la información que adelanta partes importantes de un relato de ficción, lo que Roland Barthes, en Introducción al análisis estructural del relato, llamaba "funciones cardinales": "Verdaderos "nudos" del relato" que inauguran o concluyen una incertidumbre". Marcelo Pisarro. Es la descripción de una parte importante de la trama de un programa de televisión, película, libro, etc., antes de que sea exhibido al público o antes que alguna persona en específico lo haya visto.

[10] Observación del martes 13/11 a las 2:30 p.m. en la sala.

[11] Observación del 29/11/2012, en la noche) habitación principal.

[12] Chavero, Haydeé; García Múñoz, Núria (2005). Los hábitos del consumo televisivo de una comunidad extranjera: el caso de estudiantes latinoamericanos en Barcelona. Revista de estudios de comunicación. N19. Disponible en http://www.ehu. es/zer/hemeroteca/pdfs/zer19-09-chavero.pdf.
[13] Observación 21/11/2012, (miércoles - cuarto principal).

[14] Sigue reduciéndose el número de abonos a la telefoníafija .resultados demuestranquelapenetración de telefonía fija ha ido en descenso durante los últimos cinco años. A finales de 2014 habrá unos 100 millones de abonos a telefonía fija menos que en 2009. La UIT publica las cifras de TIC de 2014. La penetración móvil de banda ancha se acerca al 32 por ciento Tres mil millones de usuarios de Internet a finales de año. Consultado el 05.05.2014. Disponible en http:// www.itu.int/net/pressoffice/press releases/2014/23es.aspx\#.U2gr7IF5Ovc.

[15] Casi siete mil millones de abonos a móvil celular. A finales de 2014 habrá casi 7 mil millones de abonos a móvil celular, de los cuales 3600 se encontrarán en la Región Asia-Pacífico. El aumento se debe principalmente al crecimiento en los países en desarrollo, que poseerán el 78 por ciento del total mundial de abonos a móvil celular. Los datos muestran que la tasa de crecimiento del móvil celular ha alcanzado su nivel más bajo en la historia $(2,6 \%$ en todo el mundo), lo que indica que el mercado está acercándose a la saturación. África, Asia y el Pacífico, donde la penetración alcanzará el 69 por ciento y el 89 por ciento, respectivamente, a finales de 2014 , son las regiones con el mayor crecimiento del móvil celular (y donde la tasa de penetración es más baja). La tasa de penetración en la Comunidad de Estados Independientes (CEI), los Estados Árabes, las Américas y Europa ha alcanzado niveles superiores al 100 por ciento, y se prevé que su crecimiento sea inferior al dos por ciento en 2014. La región con mayor tasa de penetración móvil celular es la CEI. Consultado el 05.05.2014. Disponible en http://www. itu.int/net/pressoffice/press releases/2014/23-es. aspx\#.U2gr7IF5Ovc.

[16] García, Muñoz Nuria. Comportamientos y hábitos de consumo televisivo del niño en el ámbito familiar. Ballaterra, 1996.

[17] Familia de la comuna 16. Estrato 3

\section{Para citar este artículo:}

Valle, F. Mónica; Ruiz, M. Ruiz \& Otras. (2014). Etnografía de la Teleaudiencia de Medellín. Hábitos, uso y contextos de consumo. Revista Luciérnaga/ Comunicación, Año 6, N11. Grupo de Investigación en Comunicación, Facultad de Comunicación Audiovisual, Politécnico Colombiano Jaime Isaza Cadavid. MedellínColombia. Escuela de Ciencias de la Comunicación, Universidad Autónoma de San Luís Potosí- México. ISSN 2027-1557. Págs. 1-14.

DOI. 10.33571/revistaluciernaga.v6n11a1 